\title{
THE OIL-DROP METHOD FOR THE DETERMINATION OF THE ELECTRONIC CHARGE
}

\author{
BY DR. V. D. HOPPER \\ Physics Department, University of Melbourne
}

\begin{abstract}
$T$ is generally accepted that the discrepancy between Millikan's ${ }^{1}$ arly value of the electronic charge, $e\left(4 \cdot 770 \times 10^{-16}\right.$ E.s.v. $)$, and the value derived by the X-ray method $\left(4.8021 \times 10^{-10}\right.$ E.s.U. $\left.{ }^{2}\right)$ can be accounted for by the uncertainty in the value of the viscosity of grr at $23^{\circ} \mathrm{C}$. $\left(\eta_{23}\right)$. There exist, however, wide varigtions in the results obtained by different workers/using the oil-drop method, even when the ratios $e^{2 / 3} / \eta_{23}$, which are independent of the absolute value of the viscosity, are compared. For example, the following values of $e^{2 / 3} / \eta_{23}$ have been derived from the results published by the authors : Millikan ${ }^{1}$ $334.96 \times 10^{-5}$; Bäcklin and Flemberg $334.12 \times 10^{-5}$; Ishida, Fukushima and Suetsugu ${ }^{4} 336.65 \times 10^{-5}$; Hopper and Laby ${ }^{5} 335.09 \times 10^{-5}$ (e E.S.J., $\eta_{23}$ O.G.S.). In view of the large variation in these values, in spite of the internal consistencies of the separate experiments, it seemed desirable to make a systematic study of the oil-drop method itself, to find, if possible, the reasons for these differences and also an unexceptionable value of $e^{2 / 3} / \eta_{23}$.
\end{abstract}

In this study, the velocities of a drop were measured when acted on by the earth's gravitational field and by the combined action of the gravitational field and an almost vertical electrical field. The velocities were measured by photographing the drop with the aid of a spark which was triggered at intervals of $1 / 5 \mathrm{sec}$. The hole in the top plate of the condenser through which the oil drops entered the field of view was $0.368 \mathrm{~mm}$. in diameter and displaced $2 \mathrm{~mm}$. from the centre. Measurements of drop velocities were made in the centre of the condenser, a millimetre or so sideways from the hole, thus ensuring that the distortion produced by the hole on the electric field was negligible ${ }^{6}$. Care was taken to avoid an accumulation of oil on the lower plate of the condenser, as this also produces a field distortion. The condenser plates were slightly tilted in the direction of the optic axis of the camera, so that under the repeated action of the fields the drop was gradually brought into and finally out of focus. The plates were also tilted in a direction at right angles to the optic axis, so that the path of the drop took the form of a saw tooth across the field of view; and from a study of the photograph of the drop the position of best focus could be ascertained. It was also possible to repeat the process by displacing slightly the air in the apparatus, so that the drop was brought back to its original plane. The magnification of the camera was corrected for emulsion shift. Fig. 1 shows the path taken by an oil drop. The wavy sections of the path correspond to the small translation of the drop made to bring it back into focus.

In addition to the effect of the hole on the electric field between the plates, several other factors have been found to influence the experimental value of $e^{2 / 3} / \eta_{23}$ and are summarized here.

(1) Purity of the air. Measurements must be made soon after the admission of fresh air. With air which had been in the apparatus for several weeks, a value of $e^{2 t_{3}} / \eta_{23}$ was obtained which was consistently 0.3 per cent higher than that obtained with fresh air. This effect was attributed to impurities coming from the walls of the apparatus and contaminating the air.

(2) Correction for the walls. The correction to Stokes's equation due to the influence of the walls of the apparatus increases considerably the value of $e^{2 / 3} / \eta_{23}$ of some of the previous workers. An auxiliary experiment was carried out ${ }^{7}$ which confirmed the Lorentz formula for the effect of a single wall on the motion of a falling oil drop.

(3) Oxidation of the oil. Results using Apiezon oil $B$ and castor oil confirmed the conclusion of Ishida et al. ${ }^{4}$ that oxidation or absorption occurs with oil in the form of very small drops. It was observed that using these oils the downward velocity of the drop when under the action of gravity increased gradually with time, whereas the upward velocity due to the combined action of the gravitational and electrical fields showed a decrease. Fortunately, the variations in these velocities tend to cancel each other in the determination of $e^{2 / 3} / \eta_{23}$, but a serious error might occur if a drop is studied for long periods after spraying. This effect could not be detected with butyl sebacate, and this oil was used for the determ. ination. Fig. 2 shows the variation of velocities with time of two drops of Apiezon oil $B$ (measurements for Fig. $2 B$ were taken from the drop photographed in Fig. 1), one drop of castor oil and one of butyl sebacate.

(4) Impurities in the oil. Erratic results occurred occasionally if the steel wire brush used for producing the oil drops was nearly dry. This was attributed to impurities in the oil. Some drops have been photo. graphed which showed definite fluctuations in light intensity, due, it is believed, to small steel particles held in the drop. To reduce the possibility of impurities influencing the results, the brush was cleaned regularly and impregnated with fresh oil.

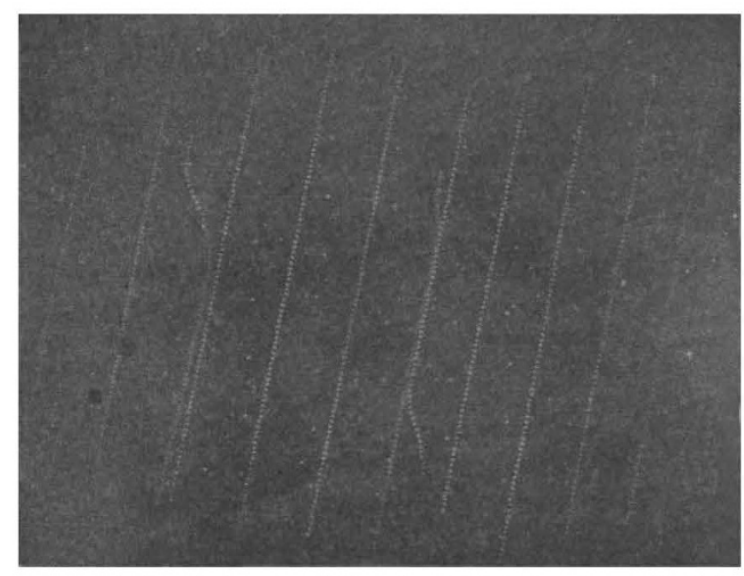

Fig. 1. Path of Apiezon $B$ oil drop ( $n=22$ (electrons), $a=3 \cdot 90 \mu$ ) which had been refocused several times. The wavy sections correspond to the small translation of the drop made to bring it into focus 


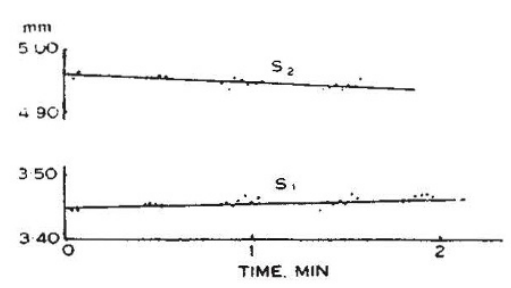

A
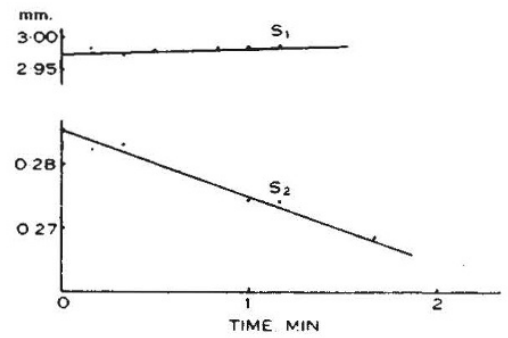

B

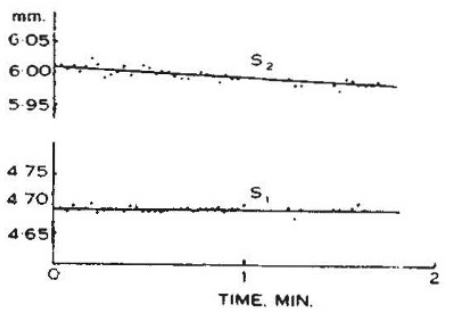

C
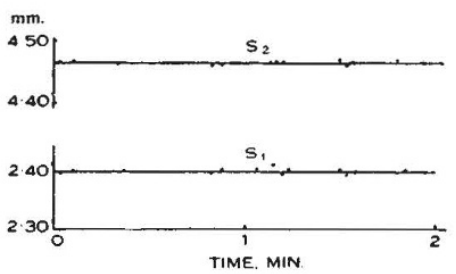

C

Fig. 2 Variation of drop velocity with time: $(A)$ Apiezon oil $B ;(B)$ Apiezon oil $B$; $(C)$ castor oil ; $(D)$ butyl sebacate. $S_{1}$ is proportional to the velocity of the drop when under the action of gravity ; $S_{2}$ is proportional to the velocity of the drop when under the combined action of the gravitational and electric

Some of the above factors make marked changes in the values of $e^{2 / 3} / \eta_{23}$ previously quoted. The result of Bäcklin and Flemberg', namely, 334.12 ${ }^{3}$ 10-5, which was the only one giving a value of $e^{2 / 3} / \eta_{23}$ agreeing with both the $\mathrm{X}$-ray value of the electronic charge and Kellström's value $\left(1835.0 \times 10^{-7}\right.$ c.G.S.) for the viscosity of air at $23^{\circ} \mathrm{C}$., is increased by the correction for the walls to $335.03 \times 10^{-5}$. As no data were given regarding the size of the hole used in these experiments, the correction for this cannot be calculated; but it has been estimated that had a hole $0.6 \mathrm{~mm}$. in diameter been used and measurements made below its centre, the above value of $e^{2 / 3} / \eta_{23}$ must be increased to $335.9 \times 10^{-5}$. Following the criticism by Birge $^{2}$, the result of Hopper and Laby $^{5}$ has been recalculated. Using the same method of analysis for both the castor oil drops and the Apiezon oil $B$ drops, the value of $e^{2 / 3} / \eta_{23}=335 \cdot 13 \times$ $10^{-5}$ is obtained, whereas for the Apiezon oil $B$ results alone the value is $335 \cdot 40 \times 10^{-5}$. The correction for the wall effect is uncertain, since in that experiment the plates were vertical, but it will increase these values by at least 3 parts in 1,000. (The actual correction may, however, be less than this as the purity of the air may be open to question.) Ishida et al. ${ }^{4}$ were the only workers to make corrections for the change in density of the oil, and their value corrected for the effect of the walls becomes $336.95 \times$ 10-8. A correction was necessary to this work owing to an error in voltage measurements ${ }^{8}$. From a recent private communication Prof. Ishida states that this correction, which was determined much later, was found to be as much as $-1 \cdot 1$ per cent. The experiment has been repeated by Ishida, Suetsugu and Matsui, giving, it is stated, $e=$
$4.794 \times 10^{-10}$ E.S.U. $\left(\eta_{23}=1,830 \times\right.$ $10^{-7}$ c.G.S.), whence $e^{2 / 3} / \eta_{23}=$ $334.72 \times 10^{-5}$. If the same correction for the walls is assumed for this as for the 1937 work, the value will be increased slightly to $335 \cdot 02 \times 10^{-5}$. Millikan's value will be increased slightly to $335.10 \times 10^{-5}$ if the wall cor. rection is applied. There is internal evidence in this work of a gradual variation in density of the oil, but a correction for this was not made.

In the present investigation, from measurements of forty-seven drops using voltages of 4,000 and 2,000 , and for values of $1 / p a$ ranging from $21 \cdot 2$ to $174 \cdot 4$, the value of $e^{2 / 3} / \eta_{23}=(335 \cdot 75 \pm$ $0 \cdot 11) \times 10^{-5}$ was obtained. Fifty. one values of $e_{1}{ }^{2 / 3} / \eta_{23}$ (that is, values of $e^{2 / 3} / \eta_{23}$ uncorrected for the slip term ${ }^{1}$ ) from these fortyseven drops are plotted against $1 / p a$ in Fig. 3. The value of $e^{2 / 3} / \eta_{23}$ corresponds to $1 / p a=0$ and will be increased slightly if Oseen's ${ }^{9}$ modification to Stokes's analysis is applied, but the increase will be less than +0.04 per cent.

A summary of the results of several careful determinations of the viscosity of air made since 1913 is given in the accompanying table. Derived values of $\eta_{23}$ obtained from the corrected oil-drop values of $e^{2 / 3} / \eta_{23}$ (assuming $e=4.8024 \times 10^{-10}$ E.S.U.) are also tabulated. There is a wide variation between recently determined values of the viscosity, four of those tabulated being close to $1834.2 \times 10^{-7}$ c.G.S. and the remaining two being close to $1829.5 \times 10^{-7}$. The value adopted by Millikan for his 1917 work was $1822.7 \times 10^{-7}$ c.G.S. The present investigation implies a value of $1826.5 \times 10^{-7}$ c.G.S. if $e=4.8024$ $\times 10^{-10}$ E.S.U. is assumed for the electronic charge.

There is reason to believe that the electrical and mechanical measurements involved in the determination of the electronic charge by the falling drop method can be made with sufficient accuracy. The difficulties inherent in the measurement of the viscosity of air represent a greater limitation to the reliability of the method.

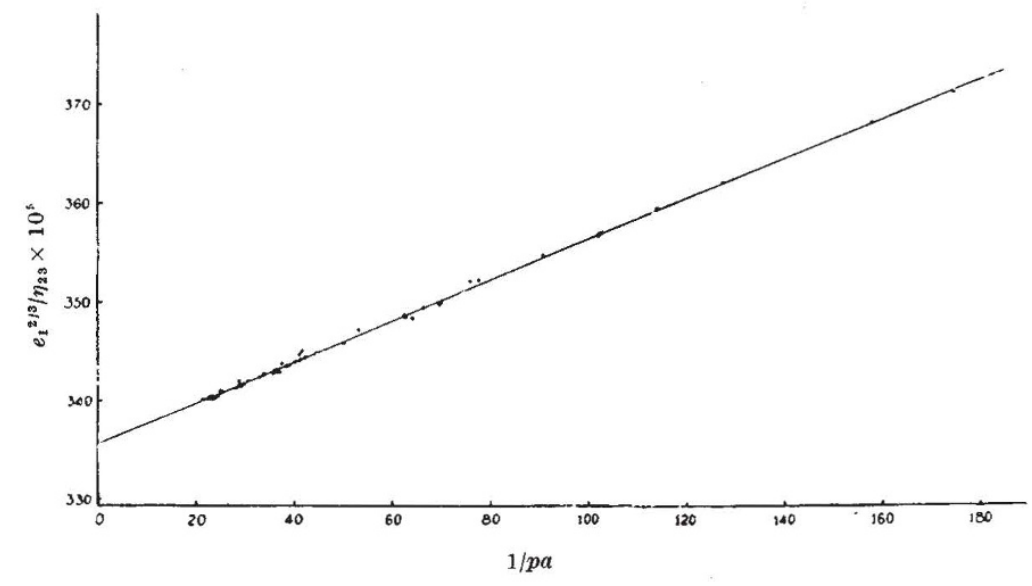

Fig. 3. Fifty-one values of $e_{1}^{2 / 3} / \eta_{23}$ (butyl sebacate drops) plotted against 1/pa. 
Viscosity of air at $23^{\circ} \mathrm{C}$

\begin{tabular}{|c|c|c|c|c|c|c|}
\hline Author & Date & Method & Comments & $\eta_{23} \times 10^{7}$ & $\underset{\substack{\text { Claimed } \\
\text { uncertainty* } \\
\times 10^{7}}}{ }$ & Reference \\
\hline $\begin{array}{l}\text { Gilchrist } \\
\text { Rapp } \\
\text { Markwell } \\
\text { Harrington } \\
\text { Kellström } \\
\text { Houston } \\
\text { Bond } \\
\text { Rigden }\end{array}$ & $\begin{array}{l}1913 \\
1913 \\
1916 \\
1916 \\
1937 \\
1937 \\
1937 \\
1938\end{array}$ & $\begin{array}{l}\text { R.C. } \\
\text { C.F. } \\
\text { C.F. } \\
\text { R.C. } \\
\text { R.C. } \\
\text { R.C. } \\
\text { C.F. } \\
\text { C.F. }\end{array}$ & $\begin{array}{l}\text { Repeat of Rapp experiment } \\
\text { Same apparatus as Gilchrist } \\
\text { Apparatus designed by Millikan and Day } \\
\text { Completion of Bond's preliminary in- }\end{array}$ & $\begin{array}{l}1825 \cdot 6 \\
1823 \cdot 1 \\
1827 \cdot 3 \\
1822 \cdot 6 \\
1835 \cdot 0 \\
1829 \cdot 13 \\
1834 \cdot 34 \\
1829 \cdot 96\end{array}$ & $\begin{array}{l}3 \cdot 6 \\
1 \cdot 8 \\
\\
1 \cdot 8 \\
3 \cdot 0 \\
4 \cdot 5 \\
0 \cdot 8 \\
0 \cdot 7\end{array}$ & $\begin{array}{r}10 \\
11 \\
12 \\
13 \\
2 \\
2 \\
2 \\
2\end{array}$ \\
\hline $\begin{array}{l}\text { Banerjea and Plattanaik } \\
\text { Bearden }\end{array}$ & $\begin{array}{l}1938 \\
1939\end{array}$ & $\begin{array}{l}\text { C.F. } \\
\text { R.C. }\end{array}$ & 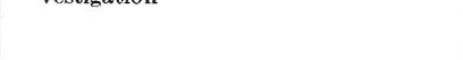 & $\begin{array}{r}1833 \cdot 75 \\
1833 \cdot 79\end{array}$ & $\begin{array}{l}2 \cdot 2 \\
0 \cdot 06\end{array}$ & $\begin{array}{l}2 \\
2\end{array}$ \\
\hline Millikan & 1917 & F.D. & $\begin{array}{l}\text { No allowance made for slight density } \\
\text { variation }\end{array}$ & $1830 \cdot 0$ & $1 \cdot 2$ & 1 \\
\hline Bäcklin and Flemberg & 1936 & F.D. & $\begin{array}{l}\text { Small apparatus, Correction for hole } \\
\text { uncertain and likely to be important }\end{array}$ & $<1830 \cdot 4$ & & 3 \\
\hline $\begin{array}{l}\text { Ishida, Fukushima and } \\
\text { Suetsugu }\end{array}$ & 1937 & F.D. & $\begin{array}{l}\text { Similar apparatus to Millikan. Cor- } \\
\text { rected for density variation }\end{array}$ & $1820 \cdot 0$ & $0 \cdot 8$ & 4 \\
\hline Hopper and Laby & 1941 & F.D. & $\begin{array}{l}\text { Small apparatus. Vertical plates. Wall } \\
\text { correction uncertain }\end{array}$ & $<1824 \cdot 6$ & & 5 \\
\hline $\begin{array}{l}\text { Ishida, Fukushima and } \\
\text { Suetsugu }\end{array}$ & (1948) & & $\begin{array}{l}\text { Voltage correction applied to their pre- } \\
\text { vious result (unpublished) }\end{array}$ & $1833 \cdot 6$ & & \\
\hline $\begin{array}{l}\text { Ishida, Suetsugu and } \\
\text { Matsui }\end{array}$ & $(1948)$ & F.D. & $\begin{array}{l}\text { New determination. Corrected for dens- } \\
\text { ity variation (unpublished). } \\
\text { (Uncorrected for density variation) }\end{array}$ & $\begin{array}{c}1830 \cdot 4 \\
(1829 \cdot 2)\end{array}$ & & \\
\hline Present investigation & (1948) & F.D. & $\begin{array}{l}\text { Small apparatus. A decrease }<0.04 \text { per } \\
\text { cent may be necessary owing to the } \\
\text { Oseen correction }\end{array}$ & $1826 \cdot 5$ & $0 \cdot 6$ & \\
\hline
\end{tabular}

R.C. Rotating cylinder method. $\}$ (Viscosities have been corrected for temperature using Sutherland's formula.)
C.F. Capillary flow method.

F.D. Falling drop method, assuming $e=4 \cdot 8024 \times 10^{-10}$ E.s.v. (see ref. 14).

* Inconsistent methods of estimation of errors used.

Miss A. Grant assisted in many of the measure. ments and in computing the results. I am also indebted to Prof. L. H. Martin for many helpful discussions during the course of this investigation, details of which will be published in the Australian Journal of Scientific Research.

1 Millikan, R. A., Phys. Rev., 34, 1 (1917).

${ }^{2}$ Birge, R. T., Amer. J. Phys., 13, 63 (1945).

${ }^{3}$ Bäcklin, E., and Flemberg, H., Nature, 137, 656 (1936).

' Ishida, Y., Fukushima, I., and Suetsugu, T., Sci. Pap. I.P.C.R. (Japan), 32, 57 (1937).

${ }^{5}$ Hopper, V. D., and Laby, T. H., Proc. Roy. Soc., A, 178, 243 (1941).

' Hopper, V. D., Nature, 158, 786 (1946).

' Hopper, V. D., and Grant, Alison M., Aust. J. Sci. Res., A, 1, 28 (1948).

${ }^{8}$ Ishida, Y., Sci. Pap. I.P.C.R. (Japan), 33, 1785 (1937-38).

Oseen, C. W., Ark. Mat. Ast. Fys., 6, No. 29 (1910).

10 Gilchrist, L., Phys. Rev., 1, 124 (1913).

${ }^{11}$ Rapp, I. M., Phys. Rev., 2, 364 (1913).

12 Markwell, E., Phys. Rev., 8, 479 (1916).

${ }^{13}$ Harrington, E. L., Phys. Rev., 8, 738 (1916).

14 Du Mond, J. W. M., and Cohen, E. R., Rev. Mod. Phys., 20, 82 (1948)

\section{ACTION OF SURAMIN ON ENZYMES}

\author{
By DR. B. W. TOWN, E. D. WILLS \\ AND
}

Prof. A. WORMALL

Dept. of Biochemistry and Chemistry, Medical College of St. Bartholomew's Hospital, London

$\mathrm{W}$ HEN ifjected intravenously, suramin (synonymg: 'Antrypol' : Bayer 205; 'Germanin': Fourneay 309) quickly effects the removal of try. panosopies from the blood and tissues of man and other animals suffering from sleeping sickness due to Trypanosoma gambiense or $T$. rhodesiense infections, if the infection is not too far advanced. The precise way in which suramin exerts its specific action on the trypanosome or on the defence mechanisms of the host or on both is still unknown, although several theories have been advanced ${ }^{1}$.

One possible explanation is that the drug combines with or otherwise inhibits enzymes in the trypanosome which are necessary for the normal metabolic changes in that organism. Trypanosomes consume considerable quantities of carbohydrates; it was found, for example, that trypanosomes can be kept alive in vitro much longer if glucose is added to the medium ${ }^{2}$. The rapid utilization of oxygen by the trypanosomes can easily be demonstrated by manometric methods, or more simply by keeping small samples of citrated blood from infected sleeping sickness patients and suitable controls out of contact with oxygen for a short time; the trypanosome-containing blood often becomes noticeably darker than the controls, owing to deoxygenation of the oxyhæmoglobin by the trypanosomes.

Any inhibition of this comparatively vigorous oxidative metabolism in the trypanosome might be expected to reduce its reproductive capacity and/or its resistance to the attack of the body defence mechanisms, and a knowledge of the action of trypanocidal drugs on enzymes might prove very useful. We are therefore studying the action of suramin on various enzyme systems, including those of the trypanosome, to determine whether concentrations of the drug similar to those reached in the blood of injected animals, or inside the trypanosome, are likely to prove toxic to any particular enzymes. So far we have largely confined our tests to the yeast enzymes concerned with carbohydrate metabolism and some other enzymes selected for particular reasons.

Previous investigators have studied the action of suramin on a few enzymes. In relatively high concentrations $(0.007 M$, that is, 1 per cent) the drug inhibits trypsin ${ }^{3}$, and in $1.75 \times 10^{-4} M$ concentrations it was found to be toxic to the enzyme fumarase but not to urease4. Acceleration of post-mortem lactic acid production in muscle and liver has been reported ${ }^{5}$, but retardation of blood glucolysis ${ }^{6}$. Hyaluronidase 